\title{
ANALISIS ENERGI PENGANGKUTAN, ENERGI PENGERINGAN DAN ENERGI PENGGILINGAN PADA PABRIK PENGGILINGAN PADI KAPASITAS MENENGAH
}

\author{
Oleh \\ Indriyani dan Wisnaningsih \\ Dosen Tetap Yayasan pada Program Studi Teknik Mesin \\ Fakultas Teknik Universitas Sang Bumi Ruwa Jurai
}

\begin{abstract}
ABSTRAK
Energi pengangkutan, energi pengeringan dan energi penggilingan merupakan suatu kegiatan pada Pabrik Penggilingan Padi Kapasitas Menengah (PPPKM). Efisiensi energi merupakan suatu proses mengoptimalkan penggunaan energi.

Tujuan penelitian ini adalah untuk mendapatkan data perbandingan energi pengangkutan, energi pengeringan dan energi penggilingan dan menganalisis efisiensi energi pada Pabrik Penggilingan Padi Kapasitas Menengah (PPPKM) yang berhubungan dengan energi pengangkutan, energi pengeringan, dan energi penggilingan.

Berdasarkan analisis energi bahwa rerata energi pengangkutan PPPKM 48,65 $\mathrm{kJ} / \mathrm{kg}$. Rerata energi pengeringan PPPKM $20,90 \mathrm{~kJ} / \mathrm{kg}$. Rerata energi penggilingan PPPKM $158,62 \mathrm{~kJ} / \mathrm{kg}$. Rerata efisiensi energi pada PPPKM 249,24 kJ/kg.

Kesimpulannnya adalah bahwa energi pengeringan pada PPKM lebih efisien dibanding energi pengangkutan dan energi penggilingan. Hal ini disebabkan pada energi pengangkutan masih menggunakan tenaga manusia, motor dan mobil. Energi manusia masih sangat diperlukan dalam proses memindahkan barang dari sawah ke kendaraan roda dua maupun roda empat.
\end{abstract}

Kata kunci: energi pengangkutan, pengeringan, penggilingan, efisiensi energi

\section{ANALYSIS OF ENERGY TRANSPORT, ENERGY DRYING AND ENERGY GRINDING AT RICE MILLING PLANT CAPACITY MEDIUM (PPKM)}

\author{
By \\ Indriyani and Wisnaningsih \\ Foundation Lecturers in Mechanical Engineering Study Program \\ Faculty of Engineering, University Sang Bumi Ruwa Jurai \\ Bandar Lampung City
}

\begin{abstract}
Energy transport, energy drying and grinding energy is an activity in Rice Milling Plant Capacity Medium (PPPKM). Energy efficiency is a process to optimize energy use.

The purpose of this study was to obtain comparative data transporting energy, draining energy and energy milling and analyze the energy efficiency of Rice Milling Plant Capacity Medium (PPPKM) associated with energy transport, energy drying and grinding energy.

Based on the analysis of the transport of energy that the average energy PPPKM $48.65 \mathrm{~kJ} / \mathrm{kg}$. Average energy drying PPPKM $20.90 \mathrm{~kJ} / \mathrm{kg}$. Average energy milling PPPKM $158.62 \mathrm{~kJ} / \mathrm{kg}$. Average energy efficiency in PPPKM $249.24 \mathrm{~kJ} / \mathrm{kg}$.
\end{abstract}


The conclusion is that energy drying on PPKM more efficient than transport energy and energy grinding. This is due to the transport of energy are still using manpower, motorcycles and cars. Human energy is still very necessary in the process of moving goods from the fields to the two-wheeler and four wheels.

Keywords: energy transportation, drying, milling, energy efficiency

\section{PENDAHULUAN}

\section{A. Latar Belakang dan Masalah}

Pada Pabrik Penggilingan Padi (PPP), energi pengangkutan sebagian besar menggunakan energi manusia, motor dan mobil. Energi pengangkutan pada Pabrik Penggilingan Padi Kapasitas Menengah (PPPKM) lebih banyak menggunakan motor, kemudian disusul energi mobil. Pada PPPKM, energi manusia bersifat pelengkap (handling). Thahir (2010). Energi pengeringan dan energi penggilingan merupakan bagian yang terpenting pada PPKM.

Teknologi mesin pengering gabah yang baik ditandai dengan pemilihan jenis dan teknologi mesin pengering dengan tepat yang disusun secara terpadu menjadi suatu konfigurasi mesin pengering gabah dengan tetap mengantisipasi kualitas bahan baku gabah yang akan dikeringkan (Tamam, 2010). Dalam memilih teknologi pengeringan hendaknya diarahkan pada aspirasi kelompok pengguna, efisiensi proses dan peningkatan mutu produk akhir Thahir (2010). Efisiensi proses pengeringan tolak ukurnya meliputi: kecepatan proses, kapasitas produksi, penghematan biaya, kemudahan sumber energi dan kelestarian lingkungan. Perbaikan mutu tolak ukurnya meliputi keseragaman produk, peningkatan mutu dan nilai tambah (LIPI, 2003).

Di Provinsi Lampung, khususnya di Kabupaten Pesawaran dan Kabupaten Pringsewu banyak ditemukan PPP, dengan berbagai kapasitas: kecil, menengah dan besar. Energi pengangkutan masih menggunakan energi manusia untuk mengangkut padi dari sawah atau rumah ke PPP. Energi pengeringan masih mengutamakan sinar matahari dalam proses pengeringan di lantai penjemuran. Energi penggilingan masih menggunakan energi manusia untuk memindahkan padi dari mesin pemecah (husker) ke mesin pemoles (polisher). Pengoperasionalan PPP belum memanfaatkan optimalisasi energi sesuai dengan spesifikasi standar mesin. Resiko energi yang tidak efisien selalu terjadi, dan hal ini perlu diatasi di masa yang akan datang (Bulog Drive V - Lampung, 2012). Oleh karena itu, Peneliti telah melakukan penelitian Analisis Energi 
Pengangkutan, Energi Pengeringan dan Energi Penggilingan pada Pabrik Penggilingan Padi Kapasitas Menengah.

\section{B. Tujuan Penelitian}

1. Untuk mendapatkan data perbandingan energi pengangkutan, energi penggilingan dan energi penggilingan pada PPPKM.

2. Untuk menganalisis efisiensi energi pengangkutan, energi pengeringan dan energi penggilingan pada PPPKM.

\section{Manfaat Penelitian}

Untuk mengetahui jenis energi pengangkutan, energi pengeringan dan energi penggilingan yang efisien sehingga dapat dijadikan pertimbangan dalam pengoperasionalan Pabrik Penggilingan Padi Kapasitas Menengah (PPPKM) di masa yang akan datang.

Berdasarkan jumlah mesin dan kemampuan harian menggiling padi, unit penggilingan padi digolongkan atas Pabrik Penggilingan Padi Kapasitas Besar (PPPKB) lebih besar dari 2,00 ton/jam, Pabrik Penggilingan Padi Kapasitas Menengah (PPPKM) 1,00 1,99 ton/jam, Pabrik Penggilingan Padi Kapasitas Kecil (PPPKK) 0,60 - 0,99 ton/jam, dan Pabrik Penggilingan Padi Keliling (PPPKL) lebih kecil 0,60 ton/jam beras giling. Pada era ini diperkenalkan pengolahan produk samping, mulai dari pemanfaatan menir menjadi tepung komposit, bekatul, dan sekam (Thahir, 2010).

\section{TINJAUAN PUSTAKA}

\section{A. Energi Pengangkutan}

Kegiatan memindahkan padi setelah panen dari sawah atau rumah ke Pabrik Penggilingan Padi (PPP) disebut pengangkutan. Tingkat kehilangan hasil dalam tahapan pengangkutan cukup rendah, berkisar antara $0,5-1,5 \%$, artinya pemilik gabah sangat berhati - hati dalam pengangkutan gabah (Thahir, 2010).

Di sektor transportasi, mulai tahun ini pemerintah akan menggiatkan pengalihan atau konversi Bahan Bakar Minyak (BBM) ke gas. Untuk mendorong program ini pemerintah akan membangun lebih banyak stasiun pengisian bahan bakar gas maupun mendorong program konversi subsidi Bahan Bakar Gas (BBG). Program konversi energi ini dilakukan secara bertahap disejumlah sektor. Program diversifikasi energi di sektor kelistrikan, yang semakin mengurangi penggunaan energi fosil, terutama BBM, sebagai sumber pembangkit (Lembaga Ilmu Pengetahuan Indonesia (LIPI), 2003). 


\section{B. Energi Pengeringan}

Proses pengeringan padi yang dilakukan saat ini umumnya menggunakan sistem tumpuk dengan ketebalan mencapai satu meter lebih. Kualitas beras yang dihasilkan rendah karena tidak meratanya pengeringan padi ditumpukan atas dan yang di bawah. Menggabungkan pengeringan dan penggilingan padi menggunakan sistem ban berjalan, menjadikannya solusi satu langkah (one stop solution). Alat dilengkapi dengan pendistribusi luaran agar padi basah yang masuk terdistribusi secara merata ketebalannya, sehingga padi dikeringkan dengan tingkat panas yang merata dan langsung masuk ke penggilingan padi (Thahir, 2010).

Pengeringan gabah dengan box dryer dapat menghasilkan beras giling bermutu baik dan kehilangan hasil kurang dari $1 \%$, lebih rendah dibandingkan dengan penjemuran. Kehilangan hasil pada tahapan penjemuran relatif tinggi, yaitu 1,5 - 2,2 \% karena sebagian gabah tercecer, dimakan ayam atau burung. Dengan mesin pengering, kehilangan hasil kurang dari $1 \%$ (Thahir, 2010).

\section{Energi Penggilingan}

Pengenalan teknologi penggilingan padi modern dinilai sudah mendesak. Gagasan yang timbul adalah pengembangan unit-unit penggilingan padi dalam skala yang lebih besar dan modern untuk menggantikan unit penggilingan skala kecil. Perkembangan teknologi penggilingan padi dalam berbagai skala secara perlahan menyingkirkan teknologi tradisional penumbuk padi dengan kincir air (Thahir, 2010).

Berdasarkan jumlah mesin dan kemampuan harian menggiling padi, unit penggilingan padi digolongkan atas Pabrik Penggilingan Padi Kapasitas Besar (PPPKB), Pabrik Penggilingan Padi Kapasitas Menengah (PPPKM), Pabrik Penggilingan Padi Kapasitas Kecil (PPPKK), dan Pabrik Penggilingan Padi Kapasitas Keliling (PPPKKl),. Pada era ini diperkenalkan pengolahan produk samping, mulai dari pemanfaatan menir menjadi tepung komposit, bekatul, dan sekam (Thahir, 2010). Modernisasi penggilingan padi terus berjalan walaupun prinsip dasar penyosohan tetap bertumpu pada mekanisme penggerusan (abrasif) dan penggesekan (friksi). Perkembangannya lebih banyak terjadi dalam sistem otomatisasi kendali komputer dan optik, instrumen pendukung untuk pengukuran derajat sosoh, pemisah beras patah dan penganalisis rasa beras (Thahir, 2010). 
Penggilingan padi menjadi muara antara produksi, pengolahan primer, dan pemasaran beras. Dalam kegiatan ini didapatkan nilai tambah gabah sebesar $400-600 \%$ dalam bentuk beras giling. Petani memasarkan, menyimpan, dan sering memperoleh modal usahataninya dari lembaga penggilingan padi. Di samping itu, industri penggilingan padi mampu menyerap lebih dari 10 juta tenaga kerja secara langsung dan merupakan industri tertua dan pertama yang tergolong besar di Indonesia (Thahir, 2010).

\section{B. Analisis Energi Pabrik Penggilingan Padi}

Adapun beberapa rumus yang digunakan dalam penelitian ini sebagai berikut:

\section{Energi Manusia ( $\left.E_{m n s}\right)$}

Energi manusia (Indriyani, dkk., 2012)

$$
\frac{\left(E_{\mathrm{mns}}\right)=}{\mathrm{t}_{\mathrm{std}}} \quad \frac{\mathrm{E}_{\mathrm{rke}}}{\mathrm{m}_{\mathrm{pdi}}} \mathrm{t}_{\mathrm{bkj}} \quad \mathrm{k}_{\mathrm{mns}}
$$

\section{Energi Motor $\left(E_{m t r}\right)$}

Energi motor (Indriyani, dkk, 2012)

$$
\frac{\left(E_{\mathrm{mtr}}\right)=\mathrm{E}_{\text {bensin }} l_{\text {bensin }}}{\mathrm{m}_{\mathrm{pdi}}}
$$

\section{Energi Mobil ( $\left.\mathbf{E}_{\mathbf{m b l}}\right)$}

Energi mobil (Indriyani, dkk, 2012)

$$
\frac{\left(E_{\mathrm{mbl}}\right)=\mathrm{E}_{\text {solar }} 1_{\text {solar }}}{\mathrm{m}_{\mathrm{pdi}}}
$$

\section{Energi Mesin Generator $\left(\mathbf{E}_{\mathbf{m g n}}\right)$}

Energi mesin generator (Indriyani, dkk, 2012) $\left(E_{\mathrm{mgn}}\right)=\mathrm{E}_{\text {solar }} 1_{\text {solar }}$

\section{Energi Kebutuhan Bahan Bakar} (Sekam Padi: $\mathbf{E}_{\mathrm{ksp}}$ )

Energi kebutuhan bahan bakar (sekam

$$
\text { padi })\left(\text { Tamrin, 2012) } E_{\mathrm{ksp}}=\frac{\mathrm{E}_{\mathrm{spi}} 1_{\mathrm{spi}}}{\mathrm{m}_{\mathrm{pdi}}}\right.
$$

\section{Energi Mesin Penggiling $\left(\mathrm{E}_{\mathrm{mpg}}\right)$}

Energi mesin penggiling (Indriyani, dkk,

$$
\text { 2012) } \frac{\left(\mathrm{E}_{\mathrm{mpg}}\right)=\mathrm{E}_{\mathrm{solar}} 1_{\text {solar }}}{\mathrm{m}_{\mathrm{pdi}}}
$$

\section{METODE PENELITIAN}

\section{A. Bahan dan Alat}

Dalam penelitian ini bahan yang digunakan adalah padi. Alat yang digunakan adalah stateskop meter (pengukur denyut jantung), motor, mobil, kalkulator, satu set komputer/laptop, dan software Microsoft Excel 2010.

\section{B. Pemilihan Lokasi Penelitian}

Pada penelitian ini dilakukan secara sengaja (purposive) pemilihan lokasi yaitu di Kabupaten Pesawaran dan Kabupaten Pringsewu, dengan pertimbangan bahwa banyak terdapat Pabrik Penggilingan Padi berdasarkan data yang didapat dari Kantor BULOG Drive V Provinsi Lampung. 


\section{Metode Pengumpulan Data}

\section{Data Primer}

Data primer didapatkan melalui survei energi operasional pada Pabrik Penggilingan Padi.

\section{Data Sekunder}

Data sekunder didapatkan melalui Kantor BULOG Drive V Provinsi Lampung, Jurnal Ilmiah, dan Buku Referensi lainnya.

\section{HASIL DAN PEMBAHASAN}

\section{A. Perbandingan Energi Pabrik}

\section{Penggilingan Padi}

\section{Energi Pengangkutan Pabrik \\ Penggilingan Padi}

Rerata energi mobil 44,53 kJ/kg dengan rerata kapasitas beban $6.315,13$ $\mathrm{kg} / \mathrm{hari}$ terdiri dari: energi manusia yang bersifat handling $10,45 \mathrm{~kJ} / \mathrm{kg}$ dengan rerata kapasitas beban 2.617,73 kg/hari, rerata energi mobil 3.697,40 $\mathrm{kJ} / \mathrm{kg}$ dengan rerata kapasitas. Energi manusia pada PPPKM hanya bersifat pelengkap (handling) karena tidak merupakan energi yang utama dalam penghitungan energi pengangkutan. Energi manusia yang digunakan tenaga manusia untuk memindahkan padi yang telah dikarungkan berukuran $50 \mathrm{~kg}$ dari mobil ke gudang atau ke lantai penjemuran yang berjarak 100 - 200 m. Rerata energi mobil 34,08 kJ/kg dengan rerata kapasitas beban 3.697,40 kJ/kg, dan rerata kebutuhan bahan bakar solar 0,32 liter/jam. Energi mobil merupakan energi yang mengangkut padi dari petani pengumpul atau koperasi dengan jarak yang jauh diantara $50-100 \mathrm{~km}$.

Rerata energi pengangkutan PPPKM $48,65 \mathrm{~kJ} / \mathrm{kg}$ dengan rerata kapasitas beban $2.238,12 \mathrm{~kg} / \mathrm{hari}$, rerata kebutuhan bahan bakar motor (bensin) 0,23 liter/jam, dan rerata kebutuhan bahan bakar mobil (solar) 0,32 liter/jam dapat dilihat pada Tabel 4.

Tabel 4. Rerata energi pengangkutan PPPKM

\begin{tabular}{|c|c|c|c|c|}
\hline No. & Jenis sub energi & $\begin{array}{c}\text { Rerata } \\
\text { beban } \\
\text { (kg/hari) }\end{array}$ & $\begin{array}{l}\text { Rerata } \\
\text { energi } \\
(\mathbf{k J} / \mathbf{k g})\end{array}$ & $\begin{array}{c}\text { Rerata } \\
\text { bahan } \\
\text { bakar } \\
\text { (liter/ja } \\
\text { m) }\end{array}$ \\
\hline 1. & Energi manusia & 0,00 & 0,00 & \\
\hline 2. & Energi motor & 102,39 & 55,37 & $\mathbf{0 , 2 3}$ \\
\hline \multirow[t]{5}{*}{3.} & Energi mobil & & & \\
\hline & $\begin{array}{cc} & \text { Energi } \\
3.1 & \text { manusia } \\
& \text { (handling) }\end{array}$ & $2.617,73$ & 10,45 & \\
\hline & 3.2 $\quad$ Energi mobil & $3.697,40$ & 34,08 & 0,32 \\
\hline & & $6.315,13$ & 44,53 & \\
\hline & Rerata & $2.238,12$ & 48,65 & \\
\hline
\end{tabular}

\subsubsection{Energi Pengeringan}

Rerata energi pengeringan PPPKM 20,90 $\mathrm{kJ} / \mathrm{kg}$ dengan rerata kapasitas beban 12.227,10 kg/hari yang terdiri dari: rerata energi manusia (pemindahan padi dari mobil ke lantai 
penjemuran) $10,45 \mathrm{~kJ} / \mathrm{kg}$ dengan rerata kapasitas beban $6.113,55 \mathrm{~kg} / \mathrm{hari}$, rerata energi manusia (pembalikan padi di lantai penjemuran) $10,45 \mathrm{~kJ} / \mathrm{kg}$ dengan rerata kapasitas beban 6.113,55 kg/hariDianggap cukup optimal dalam penggunaan energi manusia, karena rerata kapasitas bebannya cukup tinggi untuk ukuran standar energi manusia diantara 50 - 100 kg/orang. Energi matahari tidak diperhitungkan dalam penelitian ini, karena tersedia cukup banyak pada saat musim kemarau panjang dan tidak dikenakan beban beban biaya dapat dilihat pada Tabel 5 .

Tabel 5. Rerata energi pengeringan PPPKM

\begin{tabular}{llccr}
\hline No. & \multicolumn{2}{c}{ Jenis sub energi } & $\begin{array}{c}\text { Rerata } \\
\text { beban } \\
(\mathbf{k g} / \mathbf{h a r i})\end{array}$ & $\begin{array}{c}\text { Rerata } \\
\text { energi } \\
(\mathbf{k J} / \mathbf{k g})\end{array}$ \\
\hline 1. & $\begin{array}{l}\text { Energi } \\
\text { (pemindahan) }\end{array}$ & manusia & $6.113,55$ & 10,45 \\
\hline 2. & $\begin{array}{l}\text { Energi } \\
\text { (pembalikan) }\end{array}$ & manusia & $6.113,55$ & 10,45 \\
\hline Rerata & & $\mathbf{1 2 . 2 2 7 , 1 0}$ & $\mathbf{2 0 , 9 0}$ \\
\hline
\end{tabular}

\subsubsection{Energi Penggilingan}

Rerata energi penggilingan PPPKM 158,65 kJ/kg dengan kapasitas beban $3.513,09 \mathrm{~kg} / \mathrm{hari}$ yang terdiri dari: rerata energi manusia bersifat pelengkap (handling) $10,45 \mathrm{~kJ} / \mathrm{kg}$ dengan rerata kapasitas beban 1.088,71 kg/hari, rerata energi mesin penggiling 148,20 kJ/kg dengan rerata kapasitas beban 2.424,37 $\mathrm{kg} /$ hari, rerata kebutuhan bahan bakar solar 9,30 liter/jam dapat dilihat pada Tabel 6.

Tabel 6. Rerata energi penggilingan PPPKM

\begin{tabular}{llllc}
\hline No & Jenis sub energi & $\begin{array}{c}\text { Rerata } \\
\text { beban } \\
(\mathbf{k g} / \mathbf{h a r i})\end{array}$ & $\begin{array}{c}\text { Rerata } \\
\text { energi } \\
(\mathbf{k J} / \mathbf{k g})\end{array}$ & $\begin{array}{c}\text { Rerata } \\
\text { bahan } \\
\text { bakar } \\
\text { (liter/jam) }\end{array}$ \\
\hline $1 . \quad \begin{array}{l}\text { Energi manusia } \\
\text { (handling) }\end{array}$ & $1.088,71$ & 10,45 & \\
\hline $2 . \quad \begin{array}{l}\text { Energi mesin } \\
\text { penggiling }\end{array}$ & $2.424,37$ & 148,20 & $\mathbf{9 , 3 0}$ \\
\hline Rerata & $\mathbf{3 . 5 1 3 , 0 9}$ & $\mathbf{1 5 8 , 6 5}$ \\
\hline
\end{tabular}

Kesimpulan dari perbandingan: rerata energi penggilingan PPPKM (P1) $48,65 \mathrm{~kJ} / \mathrm{kg}$ lebih kecil dari erata energi pengeringan $20,90 \mathrm{~kJ} / \mathrm{kg}$, rerata energi penggilingan PPPKM 158,62 $\mathrm{kJ} / \mathrm{kg}$. Rerata energi pada PPPKM 249,24 kJ/kg dapat dilihat pada Tabel 7.

Tabel 7. Rekapitulasi rerata efisiensi energi pada PPPKM

\begin{tabular}{|l|c|c|c|c|c|}
\hline No. & Jenis & Energi & Energi & Energi & Rerata \\
& Pabrik & $\mathbf{P 1}$ & $\mathbf{P 2}$ & $\mathbf{P 3}$ & $\begin{array}{c}\text { total } \\
\text { energi } \\
\end{array}$ \\
& & $(\mathbf{k J} / \mathbf{k g})$ & $(\mathbf{k J} / \mathbf{k g})$ & $(\mathbf{k J} / \mathbf{k g})$ & $\begin{array}{c} \\
(\mathbf{k J} / \mathbf{k g})\end{array}$ \\
\hline 1. & PPPKM & 48,65 & 20,90 & 158,65 & 76,07 \\
\hline
\end{tabular}

Keterangan:

PPP : Pabrik Penggilingan Padi

P1 : Pengangkutan

P2 : Pengeringan

P3 : Penggilingan

PPPKM : Pabrik Penggilingan Padi Kapasitas Menengah 


\section{B. Efisiensi Energi}

Efisiensi energi yang dimaksud dalam penelitian ini adalah semakin kecil energi yang dikeluarkan/digunakan, berarti akan semakin efisien dalam pengoperasionalan PPPM tersebut dapat dilihat pada Tabel 10.

Tabel 10. Spesifikasi energi penggilingan PPPKM

\begin{tabular}{|l|l|r|r|}
\hline No & \multicolumn{1}{|c|}{$\begin{array}{c}\text { Spesifikasi energi } \\
\text { penggilingan }\end{array}$} & $\begin{array}{c}\text { Rerata } \\
\text { PPPKM }\end{array}$ & Satuan \\
\hline 1. & Rerata kapasitas beban & $3.513,09$ & $\mathrm{~kg} / \mathrm{hari}$ \\
\hline 2. & Rerata kebutuhan bahan bakar & 9,30 & liter/jam \\
\hline 3. & Rerata waktu penggilingan & 4,04 & jam/hari \\
\hline 4. & Rerata penggilingan padi & 377,57 & $\mathrm{~kg} / \mathrm{liter}$ \\
\hline
\end{tabular}

\subsubsection{Spesifikasi Mesin Penggiling} Pabrik Penggilingan Padi

Tabel 11. Spesifikasi mesin penggiling PPPKM

\begin{tabular}{llrl}
\hline No. & \multicolumn{1}{c}{$\begin{array}{c}\text { Spesifikasi mesin } \\
\text { penggiling }\end{array}$} & $\begin{array}{c}\text { PPPKM } \\
\text { Rerata }\end{array}$ & \multicolumn{1}{c}{ Satuan } \\
\hline $1 . \quad$ & $\begin{array}{l}\text { Rerata kapasitas beban } \\
\text { maksimum }\end{array}$ & 1,00 & ton/jam \\
& & & \\
$2 . \quad \begin{array}{l}\text { Rerata kapasitas beban } \\
\text { operasional }\end{array}$ & 0,87 & ton/jam \\
3. & $\begin{array}{l}\text { Rerata persentase beban } \\
\text { operasional }\end{array}$ & 86,96 & $\%$ \\
$4 . \quad$ & & \\
& Rerata kapasitas beban & $9.554,20$ & $\mathrm{~kg} / \mathrm{hari}$
\end{tabular}

Rerata dan Efisiensi energi pada PPPKM sebagai berikut:

a. Rerata energi pengangkutan pada PPPKM $(48,65 \mathrm{~kJ} / \mathrm{kg})$ yang terdiri dari energi manusia $(10,45 \mathrm{~kJ} / \mathrm{kg})$, energi motor $(55,37 \mathrm{~kJ} / \mathrm{kg})$ dan energi mobil $(34,08 \mathrm{~kJ} / \mathrm{kg})$ dapat dilihat pada Tabel 4. Energi manusia digunakan dalam jumlah yang banyak dengan jasa energi manusia yang dapat dikonversi ke rupiah masih murah, terutama pada negara yang sedang berkembang misalnya Indonesia, India, Vietnam, dan lainnya. Disimpulkan bahwa rerata energi pengangkutan PPPKM lebih efisien karena banyak menggunakan energi manusia. Dimana di Indonesia dan negara berkembang, konversi energi manusia masih dinilai rendah dan murah. Untuk di negara maju dan modern, energi manusia dikonversi dengan nilai yang tinggi dan mahal. Sehingga penggunaan energi pengangkutan lebih diutamakan menggunakan sarana transportasi berupa mobil.

b. Rerata energi pengeringan pada PPKM $(20,90 \mathrm{~kJ} / \mathrm{kg})$ dapat dilihat pada Tabel 5 dengan menggunakan energi manusia (pemindahan) $(10,45$ $\mathrm{kJ} / \mathrm{kg}$ ) dan pembalikan (di lantai penjemuran) $(10,45 \mathrm{~kJ} / \mathrm{kg})$ dianggap lebih efisien dibandingkan penggunaan energi alat pengering (batch dryer). Hal ini disebabkan konversi energi manusia masih dinilai rendah dan murah, dimana penggunaan energi matahari masih bersifat bebas dan tidak dikenakan biaya. 
c. Rerata energi penggilingan pada PPPKM $(158,65 \mathrm{~kJ} / \mathrm{kg})$ yang terdiri dari: rerata energi manusia (handling) $(10,45 \mathrm{~kJ} / \mathrm{kg})$, rerata energi mesin penggiling $(148,20 \mathrm{~kJ} / \mathrm{kg})$ dapat dilihat pada Tabel 6. Hal ini disebabkan energi manusia lebih banyak digunakan, karena sebagian besar mesin penggilingan padi masih memerlukan energi manusia di dalam pemindahan padi yang akan digiling melalui mesin penggiling. Misalnya pemindahan padi dari proses pecah kulit dengan dua kali pengulangan, dan dengan mesin penyosoh dengan dua kali ulangan.

d. Rerata efisiensi energi $(76,07 \mathrm{~kJ} / \mathrm{kg})$ yang teridiri dari energi pengeringan pada PPPKM (20,90 kJ/kg), energi pengangkutan $(48,65 \mathrm{~kJ} / \mathrm{kg})$, dan energi penggilingan $(158,65 \mathrm{~kJ} / \mathrm{kg})$, dapat dilihat pada Tabel 7. Hal ini disebabkan energi manusia lebih sedikit digunakan pada energi pengeringan, karena sebagian besar mesin penggilingan padi masih memerlukan energi manusia di dalam pemindahan padi yang akan digiling melalui mesin penggiling. Misalnya pemindahan padi dari proses pecah kulit dengan dua kali pengulangan, dan dengan mesin penyosoh dengan dua kali ulangan.

\section{KESIMPULAN DAN SARAN}

\section{A. Kesimpulan}

a. Rerata energi pengangkutan dari Pabrik

Penggilingan Padi Kapasitas

Menengah (PPPKM) 48,65 kJ/kg.

Rerata energi pengeringan PPPKM

$20,90 \mathrm{~kJ} / \mathrm{kg}$. Rerata energi

penggilingan PPPKM 158,62 kJ/kg.

b. Rerata efisiensi energi pada PPPKM $76,07 \mathrm{~kJ} / \mathrm{kg}$.

\section{B. Saran}

a. Perbandingan rerata energi pengangkutan, pengeringan dan penggilingan pada PPPKM yang didapatkan dari penelitian ini, sebaiknya dijadikan bahan pertimbangan dalam pengoperasionalan pada PPPKM di masa yang akan datang.

b. Analisis rerata efisiensi energi yang didapatkan dari penelitian ini adalah karena pengoperasionalannya lebih banyak menggunakan energi manusia pada energi pengeringan pada PPKM.

\section{DAFTAR PUSTAKA}

Abdullah, K. 2010. Energi dan Listrik Pertanian. JICA-DGHE/IPB Project/ ADAET. IPB. Bogor.

Adang K. 2010. Analisis Beban Kerja Operator Mesin Polisher ICHI pada Proses Penggilingan Padi 
Berdasarkan Recommended Weight Limit (RWL) Sebagai Upaya Peningkatan Produktivitas dan Keselamatan Kerja, Orasi Ilmiah, Jurusan Teknik dan Manajemen Industri, Fakultas Teknik, Universitas Pasundan Bandung.

Bulog Drive V Lampung, 2010. Pabrik Penggilingan Padi di Provinsi Lampung, Provinsi Lampung.

Chamsing, A., V.M. Salokhe, dan G. Singh. 2010. Energy Comsumption Analysis for Selected Crops in Different Regions of Thailand. Agricultural Engineering International: CIGR Ejournal, Volume VIII page 120.

Cervinka, V. 2010. Fuel and Energy Efficiency dalam Handbooks of Energy Utilization in Agricultural. Pimentel, D. CRC. Press, Inc. Boca Raton. Florida. USA.

Fluck, R.C. 2010. Energy in Florida Agriculture, downloadable matter, http://edis.ifas.ufl.edu/EH/EH 17900.pdf. Diakses pada tanggal 24 Mei 2012.

Indriyani, Tamrin, Rangga, 2012. Tesis "Analisis Energi Operasional pada Pabrik Penggilingan Padi (Kapasitas Kecil, Menengah dan Besar), Pascarjana Teknologi Industri Pertanian Fakultas Pertanian Universitas Lampung.
Indriyani, Tamrin, Rangga, 2012. Diktat Kuliah Konversi Energi, Program Studi Teknik Mesin Fakultas Teknik Universitas Sang Bumi Ruwa Jurai, Bandar Lampung.

Lembaga Ilmu Pengetahuan Indonesia (LIPI), 2003. Menggantikan Solar, Sekam bisa Diubah jadi Sumber PLTD, http://www.energi.lipi.go.id. Media Indonesia (1 September 2003). Diakses pada tanggal 20 Mei 2012.

Setyono A. 2014. Perbaikan Teknologi Pascapanen Dalam Upaya Menekan Kehilangan Hasil Padi. Jurnal Pengembangan Inovasi Pertanian Balai Besar Penelitian Tanaman Padi. Subang.

Singh, H., D. Mishra, dan N.M. Nahar. 2014. Energy Use Pattern in Production Agriculture of Typical Village in Arid Zone India - Part I. Energy. Convers. Manag.

Thahir R. 2010. Revitalisari Penggilingan Padi Melalui Innovasi Penyosohan, Mendukung Swasembada Beras dan Menghadapi Persaingan Global, Badan Penelitian dan Pengembangan Pertanian, Orasi Pengukuhan Profesor Riset Bidang Teknologi Pengolahan Hasil (Teknologi Pascapanen) Departemen Pertanian. IPB. Bogor. 